\title{
Mulemba
}

Revista Angolana de Ciências Sociais

6 (11) | 2016

Políticas, direitos e práticas da sociedade e do Estado

\section{Ler hoje Alexis de Tocqueville: três desafios da contemporaneidade}

\section{Catarina Antunes Gomes}

\section{(2) OpenEdition \\ 1 Journals}

\section{Edição electrónica}

URL: http://journals.openedition.org/mulemba/1666

DOI: $10.4000 /$ mulemba.1666

ISSN: 2520-0305

\section{Editora}

Edições Pedago

\section{Edição impressa}

Data de publição: 1 maio 2016

Paginação: 325-332

ISSN: $2182-6471$

\section{Refêrencia eletrónica}

Catarina Antunes Gomes, «Ler hoje Alexis de Tocqueville: três desafios da contemporaneidade», 


\title{
Ler hoje Alexis de Tocqueville: três desafios da contemporaneidade ${ }^{*}$
}

\author{
Catarina Antunes Gomes ${ }^{* *}$
}

Esta breve comunicação tem por objectivo apresentar o livro $A$ actualidade do pensamento de Alexis de Tocqueville na tensão entre igualdade e liberdade e entre indivíduo e sociedade nos processos de democratização contemporâneos da autoria de Cesaltina Abreu.

A obra merece especial atenção por duas ordens de razão. Em primeiro lugar, contribui para uma reactualização do cânone académico das ciências sociais. Em segundo lugar, trata-se de um texto que realiza uma sistematização do pensamento de Alexis de Tocqueville de uma maneira particularmente pedagógica. Neste sentido, o livro constituirá, certamente, uma referência para todos aqueles que se interessam por algumas das interrogações fundamentais colocadas pelas ciências sociais, tais como a natureza do laço social, as tensões vigentes na vida social contemporânea, os desafios da civis democrática e/ou a temática da cidadania e do contracto social. O carácter

* Texto da apresentação pública da obra da autoria de Cesaltina Abreu, $A$ actualidade do pensamento de Alexis de Tocqueville na tensão entre igualdade e liberdade e entre indivíduo e sociedade nos processos de democratização contemporâneos (Luanda, Edições Mulemba; Ramada, Edições Pedago, 2015/2016, 110p. [«Cadernos de Ciências Sociais: Série Sociologia»; 3]), que teve lugar no Anfiteatro principal da Faculdade de Ciências Sociais (FCS) da Universidade Agostinho Neto, no dia 28 de Março de 2016, no âmbito das suas actividades académicas pela abertura do Ano Lectivo de 2016.

* Socióloga, Professora Auxiliar do Departamento de Sociologia (Ds) da Faculdade de Ciências Sociais (FCS) da Universidade Agostinho Neto (UAN), e investigadora do Centro de Estudos Sociais (CES) da Universidade de Coimbra. 
didáctico do trabalho é, ainda, fortemente ancorado no método que estrutura a obra, pelo qual a leitura do pensamento tocquevilliano é interpelado criticamente pelo olhar de autores contemporâneos, como é o caso de Marcelo Gantus Jasmin, Luiz Werneck Vianna, Zevedei Barbu, Luis Diez del Corral, James T. Scheleifer e Amartya Sen. Para além disso, o livro reveste-se, ainda, de maior relevo quando se considera que, ao ser escrito e publicado em português, o mesmo tornará disponível o pensamento tocquevilliano a segmentos sociais que não dominam as línguas hegemónicas da academia, nomeadamente o inglês e o francês.

Foquemos, então, por breves instantes, a atenção no primeiro conjunto de razões: o facto do livro contribuir para novas leituras do pensamento de Alexis de Tocqueville especialmente adaptadas para interrogar a contemporaneidade.

De origem aristocrática, Alexis de Tocqueville produziu uma importante obra, da qual se destacam textos como Democracia na América (I e II) e o Antigo Regime e a Revolução. Nestes textos, o autor preocupou-se visivelmente em discutir e problematizar as principais transformações societais da sua época, marcada profundamente pelas revoluções francesa e americana e também pela experiência governativa parlamentar britânica. Naturalmente, sendo filho do seu tempo, algumas questões hoje consideradas centrais, não terão sido objectos principais das suas preocupações. É o caso, por exemplo, do lugar e do papel das populações ameríndias no seio da revolução americana. Mas o que é de especial interesse nestas problematizações é que Tocqueville, ao invés de procurar formular uma visão absolutamente homogénea, coesa e hermética da realidade social, fez com que as suas reflexões incidissem sobre a complexidade social gerada por essas transformações - uma complexidade nem sempre coerente e linear; uma complexidade pejada de tensões, paradoxos, dilemas e contradições. Este é um aspecto a salientar na medida em que a obra de Tocqueville insere-se historicamente num contexto onde viria a predominar uma perspectiva positivista sobre a realidade social e sobre o tipo de conhecimento que deveria ser produzido.

Para além desta especificidade, a importância de uma revisitação do pensamento de Alexis de Tocqueville explica-se por outros dois factores. Primeiro: sobretudo em certos círculos académicos, a sua obra foi sendo, de certo modo, secundarizada e objecto de um processo de estereotipização conceptual. Através de tal processo, To- 
cqueville foi sendo associado a posicionamentos intelectuais ditos mais conservadores e não progressistas. O segundo factor prendese com a actualidade das análises de Tocqueville. De facto, parte significativa das suas discussões apresentam hoje um valor heurístico importante para a compreensão de dilemas sociais, dos quais se pode destacar globalmente a relevância da participação cívica para a revitalização da civis democrática, fragilizada em tantas partes do nosso mundo.

A apresentação didáctica e sistemática destes dilemas e da sua relação com as realidades sociais contemporâneas constitui, pois, o segundo conjunto de razões que motiva a necessidade de dar um enfoque especial a este livro. Consideremos, então, três destes dilemas.

\section{A tensão entre igualdade e liberdade}

A tensão entre igualdade e liberdade é uma tensão constitutiva da civis democrática. De facto, um projecto democrático funda-se em dois anseios: por um lado, o anseio por uma liberdade que permita a realização do si-mesmo na sua singularidade e, por outro, o anseio por um modo de vida justo que garanta a todos as condições necessárias para a realização plena do si-mesmo. Estes dois anseios vivem em tensão, na medida em que o domínio de um deles pode significar a anulação do outro. Por exemplo, uma noção radicalizada de individualismo pode implicar a secundarização ou mesmo a dissolução da preocupação para com o outro. De modo similar, a celebração de qualquer colectivo como sendo homogéneo e unívoco tende a estrangular a expressão da singularidade de cada indivíduo, conduzindo a uma «tirania das maiorias» - expressão cara a Alexis de Tocqueville.

Esta temática tem sido intensamente debatida e, certamente, continuará a sê-lo, pois estes dois anseios, enquanto pilares fundadores da civis democrática, só podem viver em tensão. A anulação desta tensão é a anulação da civis democrática. Ou seja, trata-se de uma tensão que é para ser vivida e pensada criticamente em cada momento e circunstância da vida social e não de uma tensão que é para ser resolvida.

Paul Ricoeur retrata esta tensão como o paradoxo do político. Nas suas palavras: 
«Talvez o carácter enigmático do político derive dessa estrutura em desequilíbrio; temos, sem dúvida, o desejo de que todo o poder possa emanar do querer viver em conjunto, que a relação vertical seja inteiramente reabsorvida na relação horizontal - é de certa maneira o desejo de auto-gestão - mas talvez isso fosse também o fim do político, incluindo o fim dos benefícios na ordem da reunião das gerações e da conciliação entre tradições e projectos. É possível, afinal de contas, que a função rectriz do político só se possa exercer quando se encontra e se gere um compromisso entre a relação hierárquica e a relação consensual. Prosseguindo nesta linha, definiríamos então o projecto democrático como o conjunto das disposições que são tomadas para que o racional prevaleça sobre o irracional, mas simultaneamente para que o laço horizontal do querer viver em conjunto prevaleça de modo habitual sobre a relação irredutivelmente hierárquica de comando e autoridade» (2009: 161).

\section{As perspectivas substancialistas e procedi- mentalistas de democracia}

Que a democracia constitui hoje um conceito chave é uma constatação que tem merecido acordo generalizado. Todavia, imensos são os debates sobre os modos e os critérios de implementar e avaliar uma experiência democrática. Tocqueville terá sido um dos percursores destes debates, ao enfatizar a importância da correcção dos procedimentos na forma de «partipação popular na esfera púbica» como critério fundamental para «definir a natureza política do governo democrático e não o conteúdo popular de suas medidas» (apud AвReu 2016: 48). De facto, são de salientar duas perspectivas dominantes: a procedimentalista e a substancialista. De acordo com a primeira, uma transição para a democracia, uma consolidação democrática e/ou um regime democrático são eminentemente avaliados de acordo com procedimentos estabelecidos.

A questão dos procedimentos democráticos como parâmetro de avaliação é, certamente, das mais relevantes. Procedimentos, enquanto regras colectivamente definidas e cumpridas, constituem uma das mais importantes estruturas do jogo político que condiciona a experiência democrática das sociedades. Mas deverá ser atribuída unicamente aos procedimentos a capacidade heurística absoluta para avaliar quer a qualidade de uma estruturação formal 
do jogo político e/ou do exercício do poder, quer a qualidade da democracia? Ou seja, «[...] será a natureza da democracia melhor distinguida de acordo com as formas dos seus procedimentos ou pela substância dos seus resultados?» (BRATTON e VAN DE WALLE 2002: 12).

Esta pergunta de partida encontra-se, na realidade, enviesada pela sua estrutura dicotómica e por pressupôr que em cada um dos termos da dicotomia - na forma ou na substância -, existe um poder explanatório absoluto ou uma espécie de metacausalidade exclusiva que determina a natureza da democracia. Assim, por exemplo, uma análise unicamente procedimental, redundando em formalismos, poderá ser pouco informativa sobre as experiências e as vivências democráticas. Daqui decorre a questão levantada por Santos: o procedimentalismo pouco pode contribuir para «enfrentar adequadamente o problema da qualidade da democracia que voltou à superfície com a chamada "terceira onda de democratização"» (SANTOS 2002: 37). De facto, a importância das perspectivas procedimentalistas ou substancialistas só têm a ganhar com o debate sobre a qualidade da experiência democrática.

\section{O individualismo paradoxal e a individualiza- ção dos riscos e da vulnerabilidade}

Uma outra temática a enunciar prende-se com a questão do individualismo. A celebração do indivíduo na sua singularidade e autonomia constitui o reconhecimento de uma importante faceta da existência humana. Todavia, ela desencadeia, igualmente, paradoxos e tensões. Se, por um lado, a expressão do si-mesmo se abre à criatividade, renovando tradições e reinventando instituições, por outro lado, o recuo para a esfera privada empobrece não só a vida social, como fragiliza a civis democrática. Com o advento das teorias pós-modernas e pós-estruturalistas, a aversão contra qualquer forma de imposição conduz a uma defesa radical do princípio da diferença, encarnada e simbolizada no próprio indivíduo. Nesta perspectiva, a noção de consenso é desacreditada, assim como a ideia de identidades colectivas, pois ambas são teoricamente apreendidas como uma imposição artificial de significado e de coerência que destrói precisamente aquilo que deve ser preservado e ampliado: a diferença encarnada pelo indivíduo (HABBER 1994). A questão é 
que, ao afirmar a irredutibilidade do indivíduo, estes desenvolvimentos da teoria crítica segregam-no, na medida em que o isola de processos intersubjectivos e sociais de encontro e comunicação. E de que serve defender a ideia de individualidade, se esta se mantém isolada da comunicação com outros, excluindo-se, consequentemente, a possibilidade de emancipação?

Tocqueville apreendeu esta situação dilemática com especial fulgor, alertando para a complexidade dos seus efeitos, alertando para a figura potencial de um Narciso, mas alertando também para a importância da participação cívica e, consequentemente, para a figura potencial de um ego que expande os seus horizontes e renova os laços sociais de mutualidade e co-responsabilidade. Lipovetsky (2010) é um dos autores que mais se tem debruçado sobre esta tensão. Para o autor, vivemos na hipermodernidade, a qual não designa nem o reino da felicidade nem o niilismo total. A hipermodernidade designa a possibilidade de ambos.

Uma outra forma de explorar o tema do individualismo foi empreendida por Ulrich Beck (1992) na sua tese sobre modernização reflexiva e individualização dos riscos. O seu argumento é particularmente útil para compreender as consequências da radicalização da celebração do indivíduo e da sua autonomia. Sumariamente, Beck dá conta das falácias dessa autonomia e dos seus efeitos contraproducentes. Na verdade, o reforço da autonomia individual não pode fazer esquecer as múltiplas maneiras pelas quais o indivíduo permanece dependente do colectivo e das suas estruturas de poder, não tendo controlo absoluto sobre a sua vida. O esquecimento do carácter intratável dessa relação entre indivíduo e sociedade conduz frequentemente a um fenómeno de individualização dos riscos sociais, pela qual as situações de vulnerabilidade são crescentemente vividas em solidão. A individualização dos riscos equivale à perda de capital social sobre o qual os sujeitos constroem as suas redes sociais de confiança e de amparo. Esta perda, por seu turno, corresponde a um empobrecimento das possibilidades de emancipação individual. Mas Beck vai ainda mais longe, reflectindo sobre questões relativas à patologização e culpabilização dos indivíduos. Se estes são autónomos, ou seja, capazes de gerir as suas próprias vidas, e se estão em situação de vulnerabilidade e/ou marginalização, de quem será a responsabilidade? Tais processos de patologização e de 
culpabilização dos indivíduos pelas suas «vulnerabilidades sociais» são parte activa dos processos de estereotipização, marginalização e exclusão de sujeitos e grupos sociais, são parte activa dos processos de despessoalização, ou seja, perda de capacidade deliberativa sobre si-mesmo, e são parte activa também na invisibilização e na desresponsabilização das estruturas sociais vigentes.

Estas são apenas três dimensões em que o pensamento tocquevilliano mantém a sua actualidade para pensar criticamente sobre as possibilidades e os limites da vida social contemporânea, bem como do seu futuro. Outros dilemas haveria a salientar, nomeadamente no que diz respeito às questões de participação e representação e aos concomitantes modelos de democracia representativa e de democracia participativa. Em todos estes dilemas e tensões, o que se encontra é um pensamento crítico e independente que dá conta da complexidade da vida social.

\section{Referências bibliográficas}

\section{BECK Ulrich}

1992, The risk society. Towards a new modernity. Londres, Sage.

Bratton Michael e VAN DE WALLE Nicolas

2002, Democratic experiments in Africa. Regime transitions in comparative perspective. Cambridge, Cambridge University Press.

\section{HABBER Honi Fern}

1994, Beyond postmodern politics: Lyotard, Rorty and Foucault. Londres, Routeledge.

LOPOVETSKy Gilles e CHARLes Sébastien

2010, Os tempos hipermodernos. Tradução de Luís Filipe Sarmento. Lisboa, Edições 70.

Ricoeur Paul

2009, A crítica e a convicção: Conversas com François Azaoui e Marc de Launay. Tradução de António Hall. Lisboa, Edições 70.

SANTos Boaventura de Sousa (org.)

2002, Democratizar a democracia: os caminhos da democracia participativa. Rio de Janeiro, Civilização Brasileira. 


\section{Catarina Antunes Gomes}

Doutorada e Mestre em Sociologia pela Faculdade de Economia da Universidade de Coimbra; licenciada em Antropologia Social e Cultural pela Faculdade de Ciências e Tecnologia da mesma instituição. É Professora Auxiliar do Departamento de Sociologia da Faculdade de Ciências Sociais (FCS) da Universidade Agostinho Neto (UAN) e investigadora do Centro de Estudos Sociais (CES) da Universidade de Coimbra. É autora de vários artigos e livros, dos quais se salientam: Os espelhos quebrados de Narciso: diálogos pós-coloniais sobre história e memória em Angola (Asylon, 2014); "When Sophia hears Miguel or trying to transcend abyssal lines: why does it matter to Europe?», Révue de Philosophie (Post-) Europèenne, 2013; Evolutionism is dead! Long live evolutionism. News paths of coloniality of reason and knowledge (Terra, 2012); As equações não lineares da democracia (Coimbra, Almedina, 2012); recentemente publicou: «O mito da portugalidade no ensino colonial: A história e a razão metonímica», in Mulemba - Revista Angolana de Ciências Sociais (Luanda), vol. Iv, n. ${ }^{0}$ 8, Novembro de 2014, pp. 127-142..

[e-mail: catarinaantunesgomes@gmail.com] 